\title{
Size distribution of alkyl amines in continental particulate matter and their online detection in the gas and particle phase
}

\author{
T. C. VandenBoer, A. Petroff, M. Z. Markovic, and J. G. Murphy \\ Department of Chemistry, University of Toronto, Toronto, Canada \\ Received: 19 October 2010 - Published in Atmos. Chem. Phys. Discuss.: 11 November 2010 \\ Revised: 16 March 2011 - Accepted: 14 April 2011 - Published: 10 May 2011
}

\begin{abstract}
An ion chromatographic method is described for the quantification of the simple alkyl amines: methylamine (MA), dimethylamine (DMA), trimethylamine (TMA), ethylamine (EA), diethylamine (DEA) and triethylamine (TEA), in the ambient atmosphere. Limits of detection $(3 \sigma)$ are in the tens of pmol range for all of these amines, and good resolution is achieved for all compounds except for TMA and DEA. The technique was applied to the analysis of time-integrated samples collected using a micro-orifice uniform deposition impactor (MOUDI) with ten stages for size resolution of particles with aerodynamic diameters between $56 \mathrm{~nm}$ and $18 \mu \mathrm{m}$. In eight samples from urban and rural continental airmasses, the mass loading of amines consistently maximized on the stage corresponding to particles with aerodynamic diameters between 320 and $560 \mathrm{~nm}$. The molar ratio of amines to ammonium $\left(\mathrm{R}_{3} \mathrm{NH}^{+} / \mathrm{NH}_{4}^{+}\right)$in fine aerosol ranged between 0.005 and 0.2 , and maximized for the smallest particle sizes. The size-dependence of the $\mathrm{R}_{3} \mathrm{NH}^{+} / \mathrm{NH}_{4}^{+}$ ratio indicates differences in the relative importance of the processes leading to the incorporation of amines and ammonia into secondary particles. The technique was also used to make simultaneous hourly online measurements of amines in the gas phase and in fine particulate matter using an Ambient Ion Monitor Ion Chromatograph (AIM-IC). During a ten day campaign in downtown Toronto, DMA, TMA + DEA, and TEA were observed to range from below detection limit to $2.7 \mathrm{ppt}$ in the gas phase. In the particle phase, $\mathrm{MAH}^{+}$ and $\mathrm{TMAH}^{+}+\mathrm{DEAH}^{+}$were observed to range from below detection limit up to $15 \mathrm{ng} \mathrm{m}^{-3}$. The presence of detectable levels of amines in the particle phase corresponded to periods with higher relative humidity and higher mass loadings of nitrate. While the hourly measurements made using the AIM-IC provide data that can be used to evaluate the ap-
\end{abstract}

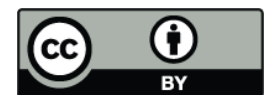

Correspondence to: J. G. Murphy (jmurphy@chem.utoronto.ca) plication of gas-particle partitioning models to amines, the strong size-dependence of the $\mathrm{R}_{3} \mathrm{NH}^{+} / \mathrm{NH}_{4}^{+}$ratio indicates that using bulk measurements may not be appropriate.

\section{Introduction}

Recent ambient measurements of amines in the gas and particle phase have prompted research into their role in the formation and growth of atmospheric particulate matter. Amine emissions have been detected from animal husbandry operations (Mosier et al., 1973; Schade and Crutzen, 1995), decomposition of organic matter on land and in the oceans (Van Neste et al., 1987; Gibb et al., 1999; Miyazaki et al., 2010; Sorooshian et al., 2009), and from biomass burning and the incineration of waste (Finlayson-Pitts and Pitts, 2000; Chang et al., 2003). In the future, increased emissions may arise from the proposed use of amines as $\mathrm{CO}_{2}$ scrubbing agents in industrial applications (Veltman et al., 2010). Ge et al. (2011a) provide a detailed review of all known amine emissions and sinks in the atmosphere. The amines emitted in the greatest quantity to the atmosphere are thought to be the simple alkyl amines: methylamine (MA), dimethylamine (DMA), trimethylamine (TMA), ethylamine (EA), diethylamine (DEA) and triethylamine (TEA). Collectively, these alkyl amines will be referred to as $\mathrm{NR}_{3}$ throughout the discussion that follows. The greatest direct source of $\mathrm{NR}_{3}$ has been suggested to be animal husbandry operations, with global emissions estimated at $0.15 \mathrm{TgN} \mathrm{a}^{-1}$, leading to amine concentrations up to hundreds of ppb near animal housing and waste storage areas (Schade and Crutzen, 1995; Rabaud et al., 2003). Gaseous amine levels in marine and background continental environments are generally on the order of <1-100 ppt (Mopper and Zika, 1987; Gronberg et al., 1992; Gibb et al., 1999; Chang et al., 2003; Akyuz, 2007). Amines are often present concomitantly with $\mathrm{NH}_{3}$, typically at mixing ratios $1-3$ orders of magnitude smaller

Published by Copernicus Publications on behalf of the European Geosciences Union. 
(Gronberg et al., 1992; Chang et al., 2003; Huang et al., 2009; Veltman et al., 2010). The primary sinks of the simple alkyl amines are thought to be oxidation by $\mathrm{OH}$ and wet deposition via rain scavenging. Lifetimes for $\mathrm{NR}_{3}$ against oxidation are on the order of a few hours to a day in the presence of atmospherically relevant concentrations of $\mathrm{OH}$, compared to a month for $\mathrm{NH}_{3}$ (Atkinson et al., 1977a; Atkinson et al., 1977b; Pitts et al., 1978; Atkinson et al., 1997). Oxidation by $\mathrm{O}_{3}$ can also be an appreciable sink for secondary and tertiary amines (lifetimes of hours to days) in a polluted environment (Finlayson-Pitts and Pitts, 2000). Elucidation of the fast loss mechanisms for $\mathrm{NR}_{3}$ led to a decline in research concerning their role in the formation of nitrosamines in the 1970s, however, their importance in the particle phase has gained renewed appreciation in the last decade of research.

There are several different scenarios in which amines might become associated with atmospheric aerosols. A comprehensive review of the thermodynamic properties of amines that govern their gas-particle partitioning can be found in Ge et al. (2011b). Amines are likely candidates for forming aminium salts with atmospheric acids resulting in the formation of secondary aerosol mass (Pratt et al., 2009). With $\mathrm{pKa}$ values ranging from $9.25-10.98\left(\mathrm{pKa}_{\mathrm{NH}_{3}}\right.$ $=9.25$ (Seinfeld and Pandis, 2006)) and similar water solubilities to $\mathrm{NH}_{3}$ (Gibb et al., 1999; Mackay et al., 2004), amines can partition to and neutralize aqueous acidic particles. The partitioning and reactive uptake mechanisms of $\mathrm{NH}_{3}$ in to particles and aqueous solutions have been well explored (Mozurkewich, 1993; Donaldson, 1999; Dinar et al., 2008) and impacts on aerosol properties continue to be investigated. Amines detected in an aqueous particle or as a salt are likely to be protonated since they are strong bases, and will therefore be denoted with an appended $\mathrm{H}^{+}$in the following discussion. The degree to which amines may be scavenged by aqueous aerosols is likely dependent on the effective $\mathrm{pH}$ of the solution and the pKa of the amine (Reaction R1). The degree of protonation will have a buffering effect on isolating amine molecules from exchange back to the gas phase (Pankow, 2003):

$\mathrm{NR}_{3(\mathrm{~g})} \leftarrow \rightarrow \mathrm{NR}_{3(\mathrm{aq})}+\mathrm{H}_{2} \mathrm{O}_{(\mathrm{l})} \leftarrow \rightarrow \mathrm{R}_{3} \mathrm{NH}_{(\mathrm{aq})}^{+}+\mathrm{OH}_{(\mathrm{aq})}^{-}$

Second, subsequent reaction with acidic solution components could lead to the formation of insoluble salts:

$\mathrm{R}_{3} \mathrm{NH}_{(\mathrm{aq})}^{+}+\mathrm{A}_{(\mathrm{aq})}^{-} \rightarrow \mathrm{R}_{3} \mathrm{NHA}_{(\mathrm{s})}$

Where $\mathrm{A}^{-}$is a conjugate base in solution and HA is the parent acid. Third, gas phase acid-base reactions to form an insoluble salt:

$\mathrm{NR}_{3(\mathrm{~g})}+\mathrm{HA}_{(\mathrm{g})} \rightarrow \mathrm{R}_{3} \mathrm{NHA}_{(\mathrm{s})}$

Finally, reactive uptake and displacement of ammonia from pre-existing salts may also occur:
$\mathrm{NR}_{3(\mathrm{~g})}+\left(\mathrm{NH}_{4}\right)_{\mathrm{n}}(\mathrm{A})_{\mathrm{m}(\mathrm{s})}$

$\longleftrightarrow \mathrm{NH}_{3(\mathrm{~g})}+\left(\mathrm{NH}_{4}\right)_{\mathrm{n}-1}\left(\mathrm{R}_{3} \mathrm{NH}\right)(\mathrm{A})_{\mathrm{m}(\mathrm{s})}$

Modeling and laboratory studies indicate that amines can enter the condensed phase by all the routes proposed above in Reactions 1-4 (Mmereki et al., 2000; Murphy et al., 2007; Barsanti et al., 2009; Ge et al., 2011b) and suggest that small chain $\left(\mathrm{C}_{1}-\mathrm{C}_{5}\right)$ alkyl amines may be important for the initiation of particle formation events and growth of nucleating aerosols. Junninen et al. (2010) used an atmospheric pressure interface time-of-flight mass spectrometer to collect ambient atmospheric ions from the gas phase, including molecular clusters where the formation of inorganic aminium salts might be occurring. Preliminary results showed homologous series of alkyl amines and pyridines in their samples in addition to the typical $\mathrm{HNO}_{3}$ and $\mathrm{H}_{2} \mathrm{SO}_{4}$ acids. These results are indicative of gas phase reaction prior to particle formation between the trace constituents, supporting the hypothesis that amines may promote $\mathrm{H}_{2} \mathrm{SO}_{4}$ nucleation through the formation of non-volatile salts. Further support for this from laboratory investigations was made by Berndt et al. (2010) in a series of lab experiments comparing the nucleation rate of $\mathrm{H}_{2} \mathrm{SO}_{4}$ as a function of relative humidity ( $\left.\mathrm{RH}\right)$ and the presence of $\mathrm{NH}_{3}$ and a surrogate amine, tert-butylamine. The results showed that both basic species had significant and similar promoting effects on the nucleation rate of $\mathrm{H}_{2} \mathrm{SO}_{4}$. However, the number density of amine was also two orders of magnitude smaller than $\mathrm{NH}_{3}$, showing that given typical near-source atmospheric concentrations of both gases, they may have similar impacts on nucleation rates. Alkyl amines, like ammonia, will form salts (Reactions R2 and R3) with inorganic and organic acidic species due to their basic nature (Angelino et al., 2001; Murphy et al., 2007; Barsanti et al., 2009). Laboratory studies have shown that in some instances, alkyl amines can displace ammonium from inorganic salts to form aminium salts (Reaction R4) (Murphy et al., 2007; Lloyd et al., 2009; Bzdek et al., 2010). Smog chamber experiments have also shown that the oxidation of amines can lead to the formation of secondary organic aerosol (SOA) or basic products that can also form salts with atmospheric acids (Murphy et al., 2007). The relative importance of these processes for the incorporation of amines in ambient fine particulate matter is not yet clear.

Amines have been detected frequently in atmospheric fine and ultrafine particulate matter by a number of online techniques, including: aerosol time-of-flight mass spectrometry (AToF-MS) (Angelino et al., 2001; Pastor et al., 2003; Denkenberger et al., 2007), compact time-of-flight aerosol mass spectrometry (C-ToF-AMS) (Murphy et al., 2007; Sorooshian et al., 2008), atmospheric pressure interface time-of-flight mass spectrometry (APi-TOF-MS) (Junninen et al., 2010), thermal desorption chemical ionisation mass spectrometry (TDCIMS) (Smith et al., 2008; Smith et al., 2010), and particle into liquid sampler ion chromatography (PILS-IC) (Murphy et al., 2007; Sorooshian et al., 
2008; Sorooshian et al., 2009). The $\mathrm{R}_{3} \mathrm{NH}^{+}$contribution of $10-47 \%$ of the positive ions in $8-10 \mathrm{~nm}$ particles sampled by Smith et al. (2010) indicates that amines may be a significant constituent of newly formed particles. Their frequent presence as detectable fractions of fine mode particles, specifically that which may not be fully neutralized by ammonia, indicates that they may also contribute to condensational growth through reactive uptake (Murphy et al., 2007). A drawback of many mass spectrometric observations is that they cannot provide quantitative mass loadings of specific $\mathrm{R}_{3} \mathrm{NH}^{+}$constituents. For example, AMS response factors for various aminium salts have been reported to range from 5-10 times that of ammonium nitrate depending on the composition of the salt, thereby limiting this method to amine identification only (Silva et al., 2008). Similarly, Murphy et al. (2007) showed that the exchange of ammonium for methylaminium in sulphate particles enhanced the collection efficiency by the C-TOF-AMS significantly due to changes in the physical properties of the particles. Simultaneous observations by C-TOF-AMS and PILS-IC by Sorooshian et al. (2008) bridged the gap in producing quantitative amine information in addition to detailed knowledge of particle composition. They found instances of EA and DEA in sub-micrometer particles at mass loadings of 50$200 \mathrm{ng} \mathrm{m}^{-3}$ ( $\sim 20 \%$ of the mass loading of $\mathrm{NH}_{4}^{+}$), indicating that alkyl amines can contribute significantly to the neutralizing capacity of particles less than $1 \mu \mathrm{m}$ in diameter. More recently, Huang et al. (2009) described an online derivatization method for the detection of $\mathrm{NR}_{3} / \mathrm{R}_{3} \mathrm{NH}^{+}$, and reported simultaneous $\mathrm{NH}_{3} / \mathrm{NH}_{4}^{+}$and $\mathrm{MA} / \mathrm{MAH}^{+}$observations near a small animal farm in New York on the order of $10 \mathrm{ppb}$ and $100 \mathrm{ppt}$, respectively.

The presence of $\mathrm{DMAH}^{+}$in nucleation event particles reported by Mäkelä et al. (2001) provided the first indication of a potentially important role that amines might play in particle formation and growth. The presence of $\mathrm{DMAH}^{+}$was also reported in the $10 \mathrm{~nm}$ fraction for non-event particulate collected, but at much lower mass loadings. Further investigations of the size-distribution of particle phase amines have shown the presence of $\mathrm{DEAH}^{+}$and $\mathrm{MAH}^{+}$in the $0.01-1.0 \mu \mathrm{m}$ range in marine aerosols, their presence being attributed to biogenic sources metabolizing the labile fraction of water-soluble organic carbon (Facchini et al., 2008; Muller et al., 2009; Miyazaki et al., 2010). A number of sizesegregated investigations of the composition of particles impacted by marine sources have recently reported a ubiquitous contribution of amines to the detectable fraction of the submicrometer aerosol water-soluble organic nitrogen (WSON) (Makela et al., 2001; Facchini et al., 2008; Muller et al., 2009; Violaki and Mihalopoulos, 2010). However, their sizedependent composition in continental air masses has not been reported to date, despite the fact that most known amine sources are terrestrial.

In general, online and offline observations of $\mathrm{R}_{3} \mathrm{NH}^{+}$have shown them to be only a small fraction of the total reduced nitrogen in particles, but because many amines are stronger bases than ammonia their presence may significantly impact aerosol composition and properties. An increase in effective basicity of aqueous aerosol has been proposed as a way to reduce the free fraction of protons and therefore significantly alter $\mathrm{pH}$ values even in the presence of relatively small $\mathrm{R}_{3} \mathrm{NH}^{+}$concentrations (Angelino et al., 2001; Pratt et al., 2009). Simultaneous measurements of amines and other chemical constituents and physical properties of aerosol can help to understand their impact on the $\mathrm{pH}$ of aerosols, which can affect particle chemistry, e.g. SOA formation. To improve our understanding of the mechanisms governing amine exchange between the gas and particle phases, online methods to separately observe and quantify individual amines in both phases with high time resolution are required. The applicability of simple thermodynamic equilibrium algorithms to describe gas-particle partitioning also needs to be evaluated by size-resolved measurements of amine mass loadings in the sub-micrometer range.

We present observations of the simple alkyl amines: MA, DMA, TMA, EA, DEA and TEA quantitatively measured using ion chromatography. This method was used for the analysis of size-resolved micro-orifice uniform deposit impactor (MOUDI) samples using a protocol described in Sect. 2.1. In Sect. 2.2, we describe the method developed to resolve and detect this suite of alkyl amines at pmol levels using ion chromatography. We also employed the technique for simultaneous hourly gas and particle phase measurements using continuous online sampling with an Ambient Ion MonitorIon Chromatography (AIM-IC) system (Sect. 2.3). In Sect. 3 we discuss the observations made using these methods including the size-resolved water-soluble composition of particulate matter in urban and rural locations in south-western Ontario (Sect. 3.1) and gas and $\mathrm{PM}_{2.5}$ observations from Toronto, Canada in July of 2009 (Sect. 3.2).

\section{Methods}

\subsection{MOUDI filter preparation and field operation}

To ensure particle collection filters were free of residual organic compounds and salts prior to use in particle collection, the following pretreatment methodology was used to ensure their removal. The filters $(47 \mathrm{~mm}, 0.1 \mathrm{~mm}$ thickness, 5-6 $\mu \mathrm{m}$ pore size, PTFE, Savillex, MN) were soaked for $24 \mathrm{~h}$ in ethanol with intermittent shaking, rinsed thoroughly with $100 \mathrm{~mL}$ of deionised water, placed in a drying rack and dried for $12 \mathrm{~h}$. The filters were then transferred to clean petri dishes (50 mm, Pall Canada Ltd, Ville St. Laurent, QC) and stored in a light shielded container for $24 \mathrm{~h}$ to equilibrate. The filters were mounted on the collection stages of the MOUDI (Model 110, MSP, MN) (Marple et al., 1986) for online sampling just prior to collection. 
The MOUDI was used to collect size-resolved aerosol samples in urban and rural environments in Ontario periodically from July 2009-May 2010. Specifically, these locations were: on the roof of the Physical Geography Building of the University of Toronto $\left(43^{\circ} 39^{\prime} 37.60^{\prime \prime} \mathrm{N}\right.$, $\left.79^{\circ} 23^{\prime} 47.42^{\prime \prime} \mathrm{W}\right)$, on top of a $3 \mathrm{~m}$ shed in Dorset $\left(45^{\circ} 14^{\prime} 14.96^{\prime \prime} \mathrm{N}, 78^{\circ} 53^{\prime} 47.33^{\prime \prime} \mathrm{W}\right)$ and an open grass field in Lambton Shores (439' $43.41^{\prime \prime} \mathrm{N}, 81^{\circ} 56^{\prime} 4.33^{\prime \prime} \mathrm{W}$ ), under a rain shelter that allowed for free ventilation. The sampling interval varied between 20 and 46 hours according to the level of particulate matter reported in real time by the Ontario Ministry of the Environment (http://www.airqualityontario. com/history/summary.cfm). The MOUDI was operated at a flow rate of $30 \mathrm{~L} \mathrm{~min}^{-1}$ with 10 stages at the following $50 \%$ cut-off points for the particle aerodynamic diameters: 10, 5.6, 3.2, 1.8, 1.0, 0.56, 0.32, 0.18, 0.1, and 0.056 um. Due to pump limitations, no back filters were used to collect particles less that $0.056 \mu \mathrm{m}$. No denuders were used upstream of the MOUDI in order to limit possible size-dependent particle losses on the denuder walls. These losses can occur both in Aitken mode particles $(<0.1 \mu \mathrm{m})$ by Brownian diffusion (Ye et al., 1991) and in the coarse mode particles $(>2.5 \mu \mathrm{m})$ by impaction (Spurny, 1999). Filter extracts were obtained by room temperature sonication in $10 \mathrm{~mL}$ of deionized water for $1 \mathrm{~h}$, filtration through a $0.45 \mu \mathrm{m}$ PTFE membrane (Pall Ion Chromatography Acrodisc $\AA$, VWR International, Mississauga, ON) and dilution to a final volume of $15 \mathrm{~mL}$ with deionised water. While extraction efficiencies were not explicitly determined in this study, the method is known to be nearly quantitative for water soluble compounds (Kouvarakis et al., 2002). Extracts were then analyzed by ion chromatography using one or both of the methods described below. Field blanks were collected by transporting filters to and from the sampling site and subjecting them to the same extraction and analysis procedures. The application of ion chromatography to offline MOUDI samples had method detection limits of sub-ng $\mathrm{m}^{-3}$ for the particulate samples collected.

\subsection{Ion Chromatography (IC)}

Chromatographic resolution of anions and cations was performed using two Dionex ICS-2000 systems operating with reagent-free eluent and suppressed conductivity detection. Anions were separated using a gradient elution method on an AS19 hydroxide-selective anion exchange column fitted with a trace anion concentrator column (TAC-ULP1), guard column and an ASRS $® 300$ conductivity suppressor using $\mathrm{KOH}$ as an eluent. A linear gradient from 1-20 mM was employed over the first $12 \mathrm{~min}$, with a linear increase to $85 \mathrm{mM}$ over the next $6 \mathrm{~min}$ and then equilibrated back to $1 \mathrm{mM}$ for the final $7 \mathrm{~min}$ of the total $25 \mathrm{~min}$ run time at a flow rate of $1 \mathrm{~mL} \mathrm{~min}^{-1}$. Two separate methods have been developed for the separation of cations using the Dionex CS17 and CS12A cation exchange columns fitted with a trace cation concen- trator column (TCC-ULP1), CG17 or CG12A guard column and a CSRS® 300 suppressor by gradient elution with methanesulfonic acid (MSA). For the CS17, a linear gradient was used at an eluent flow rate of $1.0 \mathrm{~mL} \mathrm{~min}^{-1}$ from 2$8 \mathrm{mM}$ over the first $11.55 \mathrm{~min}$, increased to $10 \mathrm{mM}$ over the next $4.45 \mathrm{~min}$ and then equilibrated back to $2 \mathrm{mM}$ for $9 \mathrm{~min}$ prior to the next run. For the CS12A column, higher eluent strengths were used due to the increased capacity of the column for ion exchange. Over the first 12 min the MSA concentration was ramped linearly from $5-10 \mathrm{mM}$ and then from $10-80 \mathrm{mM}$ over the next $10 \mathrm{~min}$ and allowed to equilibrate back to $5 \mathrm{mM}$ over the final $3 \mathrm{~min}$ of the $25 \mathrm{~min}$ run at a flow rate of $1.2 \mathrm{~mL} \mathrm{~min}^{-1}$. Column temperatures, in all cases, were maintained at $30^{\circ} \mathrm{C}$.

All chemicals used were reagent ACS or HPLC grade. Stock solutions of MA $(40 \% \mathrm{w} / \mathrm{w})$, DMA $(40 \% \mathrm{w} / \mathrm{w})$, TMA $(45 \% \mathrm{w} / \mathrm{w})$, EA $(71 \% \mathrm{w} / \mathrm{w})$, DEA ( $>99.5 \% \mathrm{w} / \mathrm{w})$, TEA $(100 \%)$, formic acid $(1 \mathrm{mg} / \mathrm{mL})$, acetic acid $(1 \mathrm{mg} / \mathrm{mL})$ and oxalic acids $(1 \mathrm{mg} / \mathrm{mL})$ were purchased from SigmaAldrich (St. Louis, MO). Ethanol (95\%) was purchased from Commercial Alcohols (Brampton, ON) and deionised water $\left(18.2 \mathrm{M} \Omega\right.$ ) was produced in house with a Barnstead ${ }^{\mathrm{TM}}$ Easypure ${ }^{\circ}$ RoDi system (VWR, Mississauga, ON). Premixed analytical standards for inorganic anions $\left(\mathrm{F}^{-}, \mathrm{Cl}^{-}, \mathrm{NO}_{2}^{-}\right.$, $\left.\mathrm{Br}^{-}, \mathrm{NO}_{3}^{-}, \mathrm{SO}_{4}^{2-}, \mathrm{PO}_{4}^{3-}\right)$ and cations $\left(\mathrm{Li}^{+}, \mathrm{Na}^{+}, \mathrm{NH}_{4}^{+}\right.$, $\mathrm{K}^{+}, \mathrm{Mg}^{2+}, \mathrm{Ca}^{2+}$ ) and eluent generator cartridges of $\mathrm{KOH}$ and MSA were supplied by Dionex Corporation (Sunnyvale, CA).

\subsubsection{Ion Chromatography for resolution of amines and inorganic cations in atmospheric samples}

Previous investigations of aliphatic amines have used ion chromatography for the detection and quantification of amines in atmospheric samples (Murphy et al., 2007; Chang et al., 2003; Facchini et al., 2008; Sorooshian et al., 2008; Sorooshian et al., 2009; Erupe et al., 2010), but none has reported the full range of species measured in this study. The design of commercial columns has been focused on the separation of inorganic cations, limiting their ability to fully resolve them from protonated organics, such as alkyl amines, especially where their solvated properties are similar. Over the last decade their use in the separation of a number of amines has been demonstrated (Chang et al., 2003; Murphy et al., 2007; Erupe et al., 2010). The amine resolution achieved using the methodology we have developed on the Dionex CS17 column using preconcentration is shown in Fig. 1. TMA and DEA are not resolved and, henceforth, will be referred to as TMA + DEA/TMAH ${ }^{+}+\mathrm{DEAH}^{+}$, a complication that has been reported previously for Dionex columns (Murphy et al., 2007). Under conditions of higher concentration, poor separation of $\mathrm{Na}^{+}$and $\mathrm{NH}_{4}^{+}$and poor peak shapes become problematic for retrieving accurate peak area integrations, particularly in offline sample analysis. 


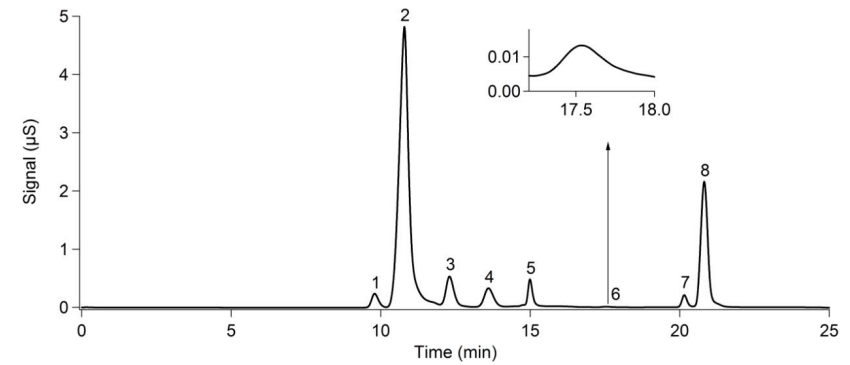

Fig. 1. Sample CS17 chromatogram of particles collected on the $440 \pm 120 \mathrm{~nm}$ MOUDI stage at Dorset, ON. Peaks are: $1-$ sodium, 2 - ammonium, 3 - potassium, 4 - dimethylamine, 5 trimethlyamine and diethylamine, 6 - triethylamine, 7 - magnesium, 8 - calcium.

For analysis of online and offline samples from environments impacted by high loadings of water-soluble cations, a method using a Dionex CS12A column was developed. Figure 2 shows the increased resolution between $\mathrm{Na}^{+}$and $\mathrm{NH}_{4}^{+}$, but persistent coelution of TMA and DEA. Coelution of MA and EA with $\mathrm{NH}_{4}^{+}$in the $\mathrm{CS} 12 \mathrm{~A}$ method occurred at relative concentration ratios 5 times lower than in our CS17 methodology, making it more prone to $\mathrm{NH}_{4}^{+}$interfering in $\mathrm{R}_{3} \mathrm{NH}^{+}$ detection. The ability to resolve and quantify amines in an atmospheric sample, therefore, depends not only on the absolute amount of amine present, but on the relative amounts of amine and ammonia. In an ideal situation, the sampling period will be sufficiently long to collect enough amine to exceed the detection limit, but short enough that $\mathrm{NH}_{4}^{+}$will not coelute. Instrument and method detection limits for ion chromatography analysis were calculated as an absolute number of moles using the slope and three times the standard deviation in the area of the background conductivity observed in sequential blank samples or field blanks at the elution time of the analyte of interest (MacDougall and Crummett, 1980). Positive instrument response for target analytes at these concentrations was confirmed by offline injection of aqueous standards. The instrument detection limits for the alkyl amines were $<50 \mathrm{pmol}$ and $\mathrm{NH}_{4}^{+} \sim 1 \mathrm{nmol}$. Detection limits for all other inorganic analytes are $<500$ pmol.

For offline samples, such as the MOUDI samples collected in this study, dilution and reanalysis to improve separation and quantitation of amines and inorganics was utilized to overcome co-elution in samples with high concentrations of ammonium. However, this is not an effective strategy for online sample analysis. Since $\mathrm{NH}_{3} / \mathrm{NH}_{4}^{+}$arise from similar sources as $\mathrm{NR}_{3} / \mathrm{R}_{3} \mathrm{NH}^{+}$(Van Neste et al., 1987; Schade and Crutzen, 1995), separation of these species is an issue that must be addressed. For online observations, the best approach was the CS17 methodology described above.
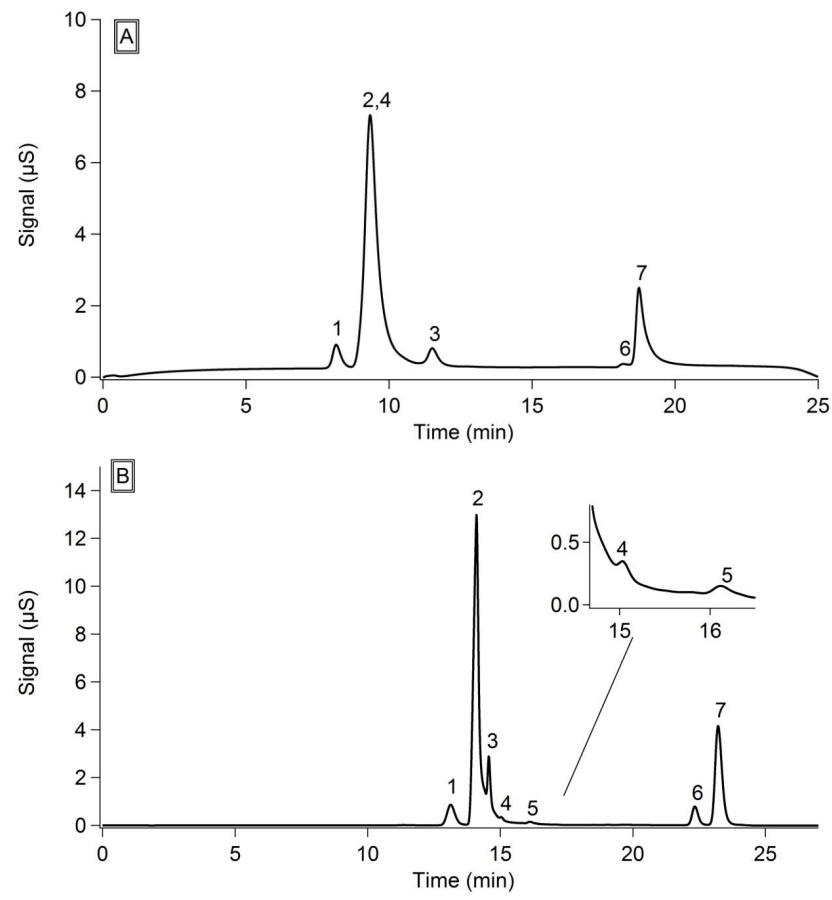

Fig. 2. Chromatograms of particles collected on the $780 \pm 200 \mathrm{~nm}$ MOUDI stage at Lambton Shores, ON separated on (A) CS12A and (B) CS17 columns. Compounds are: 1 - sodium, 2 - ammonium, 3 - potassium, 4 - dimethylamine, 5 - trimethylamine and diethylamine, 6 - magnesium, 7 - calcium.

\subsection{Online detection by URG-AIM}

The operational principles of the AIM-IC 9000D (URG, Chapel Hill, NC) system have been previously described (Ellis et al., 2011). Briefly, the AIM-IC system employs two online ion chromatography systems for the simultaneous detection of cations and anions from gas and particle samples concentrated from a continuous flow of ambient air. In our system, the air sample is pulled at $3.0 \mathrm{~L} \mathrm{~min}^{-1}$ through a minimum inlet length constructed of Teflon-coated aluminum and fitted with an impactor assembly to select particles with an aerodynamic diameter of less than $2.5 \mu \mathrm{m}$. Gases are stripped from the air stream by passing through a liquid parallel plate denuder with continuously replenished solvent flowing across the surface. The particles in the air flow are constrained into a supersaturated steam condensation coil and cyclone assembly and grown hygroscopically for collection as an aqueous solution. The sample flows containing the soluble gas and particle analytes are separated into equal aliquots for anion and cation chromatographic analyses every hour following 60 minutes of ambient sampling.

The AIM-IC was deployed utilizing the CS17 columns and operated according to the separation methodology described in Sect. 2.2 to monitor ambient air in downtown Toronto, ON at the University of Toronto's St. George Campus from 26 June-3 July 2009. Hourly detection of MA, DMA, TMA, 
Table 1. MOUDI size-resolved particulate matter sample collection and analysis information. Eight samples were collected over the course of a year using either a rotating or fixed set of MOUDI stages. Mass loadings of $\mathrm{PM}_{1.8}$ amines in the particulate MOUDI samples are reported and then calculated as a function of measureable water soluble mass $\left(\mathrm{m}_{\text {sol }}\right)$, total mass $\left(\mathrm{m}_{\text {tot }}\right)$, as well as relative to $\mathrm{PM}_{1.8} \mathrm{NH}_{4}^{+}$.

\begin{tabular}{|c|c|c|c|c|c|c|c|c|c|}
\hline Sample \# & Location & $\begin{array}{l}\text { Start } \\
\text { Date mm/dd/yyyy }\end{array}$ & $\begin{array}{l}\text { Sample } \\
\text { Time (h) }\end{array}$ & Amines Detected & $\begin{array}{l}\mathrm{R}_{3} \mathrm{NH}^{+} \\
\left(\mathrm{ng} \mathrm{m}^{-3}\right)\end{array}$ & $\begin{array}{l}\mathrm{m}_{\mathrm{sol}} \\
(\%)\end{array}$ & $\begin{array}{l}\mathrm{m}_{\mathrm{tot}} \\
(\%)\end{array}$ & $\begin{array}{l}\mathrm{NH}_{4}^{+} \\
\left(\mathrm{ng} \mathrm{m}^{-3}\right)\end{array}$ & $\begin{array}{l}\mathrm{R}_{3} \mathrm{NH}^{+} \\
/ \mathrm{NH}_{4}^{+}\end{array}$ \\
\hline $1^{*}$ & Toronto, ON & $21 / 07 / 2009$ & 24 & DMA, TMA+DEA & 16 & 0.78 & 0.31 & 470 & 0.014 \\
\hline $2^{*}$ & Toronto, ON & 07/08/2009 & 22 & DMA,TMA+DEA, TEA & 55 & 9.10 & 0.98 & 90 & 0.11 \\
\hline $3^{*}$ & Toronto, ON & 07/08/2009 & 22 & DMA,TMA+DEA, TEA & 35 & 7.52 & 0.68 & 90 & 0.17 \\
\hline $4^{*}$ & Dorset, ON & $14 / 08 / 2009$ & 46 & MMA, DMA, TMA+DEA, TEA & 42 & 7.98 & 0.71 & 120 & 0.14 \\
\hline $5^{*}$ & Toronto, ON & $16 / 08 / 2009$ & 24.25 & DMA,TMA+DEA, TEA & 81 & 0.42 & 0.24 & 5210 & 0.0045 \\
\hline $6^{* * *}$ & Toronto, ON & $16 / 03 / 2010$ & 29 & DMA,TMA+DEA, TEA & 35 & 0.88 & & 740 & 0.011 \\
\hline $7 * * *$ & Lambton Shores, ON & 09/04/2010 & 24.25 & DMA, TMA+DEA & 19 & 0.32 & 0.74 & 790 & 0.0065 \\
\hline $8 * * *$ & Lambton Shores, ON & $10 / 04 / 2010$ & 24 & DMA, TMA+DEA & 33 & 0.51 & 0.45 & 1320 & 0.0067 \\
\hline
\end{tabular}

$*=$ Indicates CS17 separation method; **=Indicates CS12A separation method

EA, DEA and TEA at the ppt and $\mathrm{ng} \mathrm{m}^{-3}$ levels was achieved with the AIM-IC system methodology. Quantities were determined from offline injections of known aqueous standards of the analytes of interest across the relevant range of observed atmospheric concentrations. Background levels of all compounds detected by the AIM-IC were determined by overflowing the inlet with high purity zero air and subtracting the average peak area acquired over $8 \mathrm{~h}$ from the peaks observed while sampling ambient air. If background peaks were not observed for a particular species, the 5 lowest points of the time series were taken as blank values, the average of which was subtracted from the ambient dataset. Simultaneous gas phase $\mathrm{NH}_{3}$ measurements were made using a quantum cascade tunable infrared diode laser absorption spectrometer (QC-TILDAS) system (Aerodyne, USA) (Ellis et al., 2010).

\section{Results and discussion}

\subsection{Size-resolved particulate amines}

Eight samples were collected using the MOUDI under the conditions listed in Table 1. The fine aerosol fraction $\left(\mathrm{PM}_{1.8}\right)$ collected by the MOUDI is determined by summing the six lowest MOUDI size bins. The total water soluble mass was determined from the sum of the species quantified by ion chromatography. The fraction of amines in the total mass of soluble $\mathrm{PM}_{1.8}\left(\% \mathrm{~m}_{\text {sol }}\right)$ ranges from $<1 \%$ to $9.1 \%$ across our observations. The amine mass fraction in $\mathrm{PM}_{2.5}\left(\% \mathrm{~m}_{\text {tot }}\right)$ was calculated by dividing $\mathrm{PM}_{1.8}$ amines by the total mass loading of $\mathrm{PM}_{2.5}$ obtained from the nearest Ontario Ministry of Environment air quality monitoring station for the period of observation. The sum of the particulate alkyl amines was never more than $1 \%$ of the $\mathrm{PM}_{2.5}$ aerosol mass loadings. $\mathrm{PM}_{1.8}$ mass loadings of all the amines, denoted as $\mathrm{R}_{3} \mathrm{NH}^{+}$, and $\mathrm{NH}_{4}^{+}$are shown in Table 1 . While the $\mathrm{R}_{3} \mathrm{NH}^{+}$mass loadings only span one order of magnitude among the samples, the mass loading of $\mathrm{NH}_{4}^{+}$varies by a factor of 60 . The final column includes the molar ratio of the sum of amines to ammonium $\left(\mathrm{R}_{3} \mathrm{NH}^{+} / \mathrm{NH}_{4}^{+}\right)$in $\mathrm{PM}_{1.8}$, the variability of which depends more on the mass loading of $\mathrm{NH}_{4}^{+}$than that of $\mathrm{R}_{3} \mathrm{NH}^{+}$.

The presence of amines was detected throughout the fine mode $(0.056-1.8 \mu \mathrm{m})$ in all cases for $\mathrm{DMAH}^{+}$and $\mathrm{TMAH}^{+}+\mathrm{DEAH}^{+}$. The presence of $\mathrm{TEAH}^{+}$was found in 5 samples and $\mathrm{MAH}^{+}$near the instrument LOD in the sample collected at Dorset, ON. In all cases the mass loadings or moles of $\mathrm{TMAH}^{+}+\mathrm{DEAH}^{+}$were calculated assuming everything was $\mathrm{DEAH}^{+}$. DEA has a larger Henry's law constant and $\mathrm{pKa}$ value, indicating that it would be more likely to partition to an aqueous particle than TMA under conditions of similar gas phase mixing ratios (Ge et al., 2011b). Furthermore, the dissociation constants $\left(K_{p}\right)$ calculated by Murphy et al. (2007) for the formation of aminium nitrate salts from gas phase precursors (Reaction R3) were at least three orders of magnitude lower for DEA than TMA. DEA showed higher analytical sensitivity under the CS17 method described in Sect. 2.2 and has a lower molecular mass than TMA. Therefore, the values we have calculated and report here are the lower estimate for the sum of these species. The true values could be up to $23 \%$ greater for mass and moles if an appreciable fraction of the sample is actually TMA.

\subsubsection{Aerosol Composition of water-soluble ionic species}

Figure 3 shows the composition of water-soluble particulate species, as a function of particle size at three different sampling sites. In all cases, the dominant cation at particle diameters less than $1.8 \mu \mathrm{m}$ was $\mathrm{NH}_{4}^{+}$, which nearly balanced the major anionic components of $\mathrm{SO}_{4}^{2-}, \mathrm{NO}_{3}^{-}$, formic, acetic and oxalic acids. Thus, the sub-micrometer aerosol we sampled were neutralized or nearly neutral, with respect to ion balance, in all cases. In some cases, amines were found to have important contributions to the total mass of the fine mode. Panel A displays a sample collected at Dorset, Ontario, a rural forest site, on 14 August 2009 with the air mass 

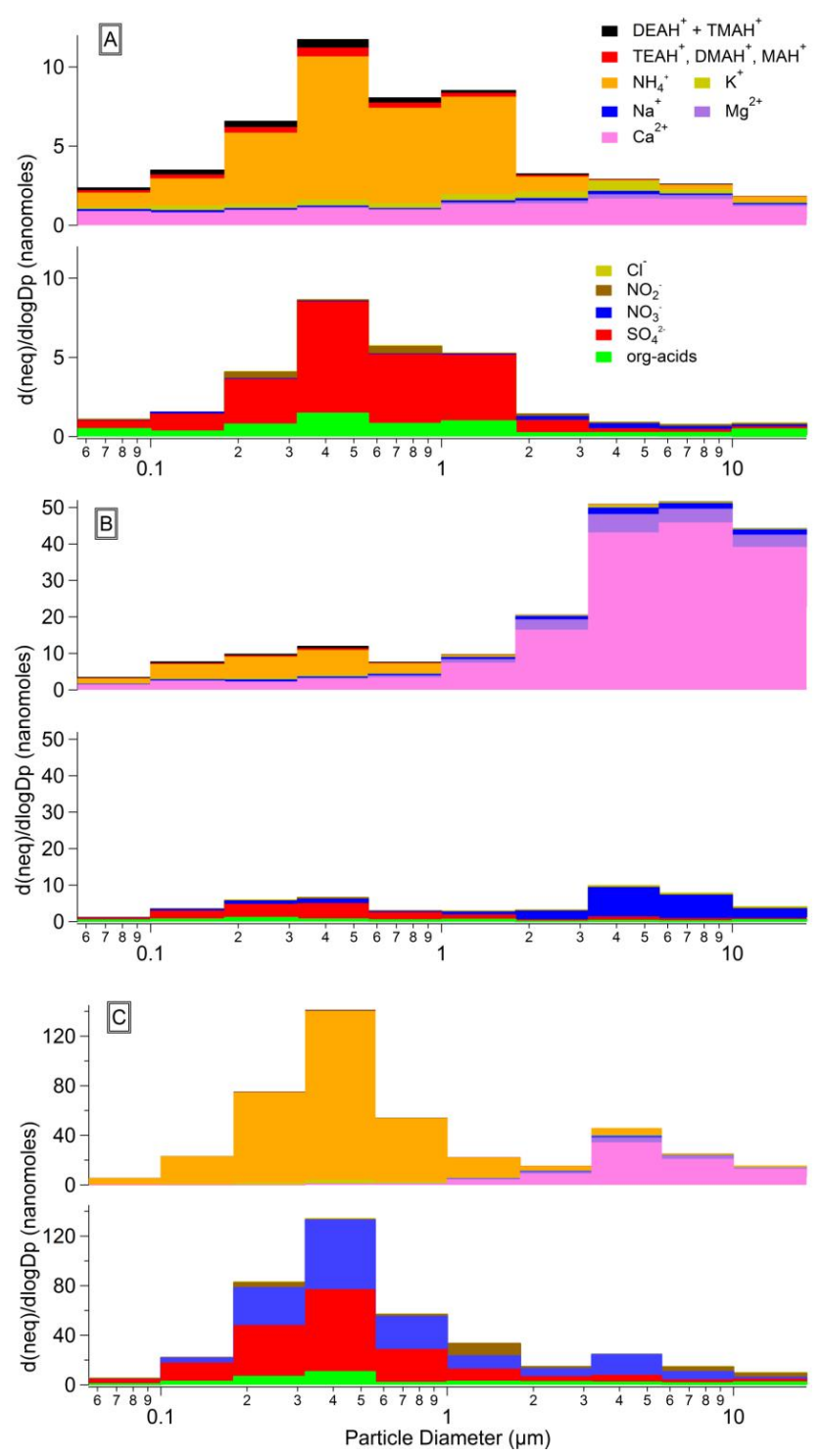

Fig. 3. Mole equivalent distribution of major water-soluble ions in MOUDI samples. (A) Sample 4 collected in Dorset, (B) Sample 3 collected in Toronto (C) Sample 8 collected in Lambton Shores.

originating over south-western Ontario. Amines contribute about $5 \%$ of the total water-soluble cation fraction in the accumulation mode aerosol from $0.056-1.8 \mu \mathrm{m}$. This sample was also particularly enhanced in formic, acetic and oxalic acids in addition to the dominant $\mathrm{SO}_{4}^{2-}$ anion. The sample composition displayed in Panel B was collected from the roof of the Physical Geography Building at University of Toronto, a dense urban location, on 7 August 2009. The aerosol is neutralized in terms of $\mathrm{NH}_{4}^{+}-\mathrm{NO}_{3}^{-}-\mathrm{SO}_{4}^{2-}$ throughout the accumulation mode, with $<5 \%$ of the water-soluble cation fraction being contributed by amines. $\mathrm{Ca}^{2+}$ and $\mathrm{NO}_{3}^{-}$dominate the coarse mode, likely as $\mathrm{CaCO}_{3}$ with some $\mathrm{Ca}\left(\mathrm{NO}_{3}\right)_{2}$ from processing of lofted particles. The relative composi-
Table 2. The maximum mass loading $\left(\mathrm{ng} \mathrm{m}^{-3}\right)$ on a single stage, for each amine species quantified in the MOUDI sample. The median diameter $(\mathrm{nm})$ of the size bin where each species maximizes is given in parentheses when it is not the $320-560 \mathrm{~nm}$ size bin. No amines were consistently detected in all size bins from 0.056 to $18 \mu \mathrm{m}$, so a range was not reported as the lower value would always be below the limit of detection. ND indicates the species was not detected on any stage of the MOUDI.

\begin{tabular}{ccccc}
\hline Sample \# & MMA & DMA & TMA+DEA & TEA \\
\hline 1 & ND & 4 & 3 & ND \\
2 & ND & 5 & 11 & 1.3 \\
3 & ND & 3 & 7 & 0.3 \\
4 & 0.05 & 6 & 5 & 0.4 \\
5 & ND & 10 & 19 & $2(780)$ \\
6 & ND & $2(100)$ & 10 & $14(4400)$ \\
7 & ND & 0.8 & $5(780)$ & ND \\
8 & ND & $0.4(1400)$ & 9 & ND \\
\hline
\end{tabular}

tion of this sample is typical for samples collected in downtown Toronto, although the magnitude of mass in the sample can vary considerably, particularly in the accumulation mode. The sample displayed in Panel $\mathrm{C}$ was collected from Lambton Shores, Ontario, a rural location, on 10 April 2010. The contribution of amines was insignificant to the aerosol neutrality, despite $\mathrm{NO}_{3}^{-}$representing about $30 \%$ of the anion water-soluble fraction at the peak of the accumulation mode.

Ion chromatography cannot measure $\mathrm{H}^{+}$in solution, but it is assumed to balance most of the remaining negative ions in the $\mathrm{PM}_{1.8}$. No significant unidentified peaks were observed in the cation or anion chromatographs. The dominant cation at particle diameters greater than $1.8 \mu \mathrm{m}$ was $\mathrm{Ca}^{2+}$, which is not balanced by a quantifiable anionic species. The most likely constituent that balances the observed $\mathrm{Ca}^{2+}$ is $\mathrm{HCO}_{3}^{-} / \mathrm{CO}_{3}^{2-}$, which cannot be quantitatively detected by the sample handling and ion chromatographic methods used in this study. $\mathrm{Ca}\left(\mathrm{HCO}_{3}\right)_{2}$ and $\mathrm{CaCO}_{3}$ are known to be major components of concrete and arise from surface erosion in urban environments. This is likely responsible for the large $\mathrm{Ca}^{2+}$ signal seen in Panel B of Fig. 3. In Panels B and C, coarse mode nitrate was also observed. It has been welldocumented that coarse mode nitrate can be formed by acid displacement reactions between $\mathrm{HNO}_{3}$ and $\mathrm{Ca}\left(\mathrm{HCO}_{3}\right)_{2}$ and $\mathrm{CaCO}_{3}$ to form $\mathrm{Ca}\left(\mathrm{NO}_{3}\right)_{2}$ (Goodman et al., 2000; Hanisch and Crowley, 2001; Bauer et al., 2004; Vlasenko et al., 2006; Liu et al., 2008), which further supports the presence of unmeasured carbonate in our samples.

Despite being a small fraction of the total cation composition and the total aerosol mass, the alkyl amines measured may influence the effective $\mathrm{pH}$ of aqueous aerosols by several units (Pankow, 2003; Pratt et al., 2009), especially where they represent more than $1 \%$ of the water-soluble aerosol mass. Stronger basic properties compared to $\mathrm{NH}_{4}^{+}$make the 

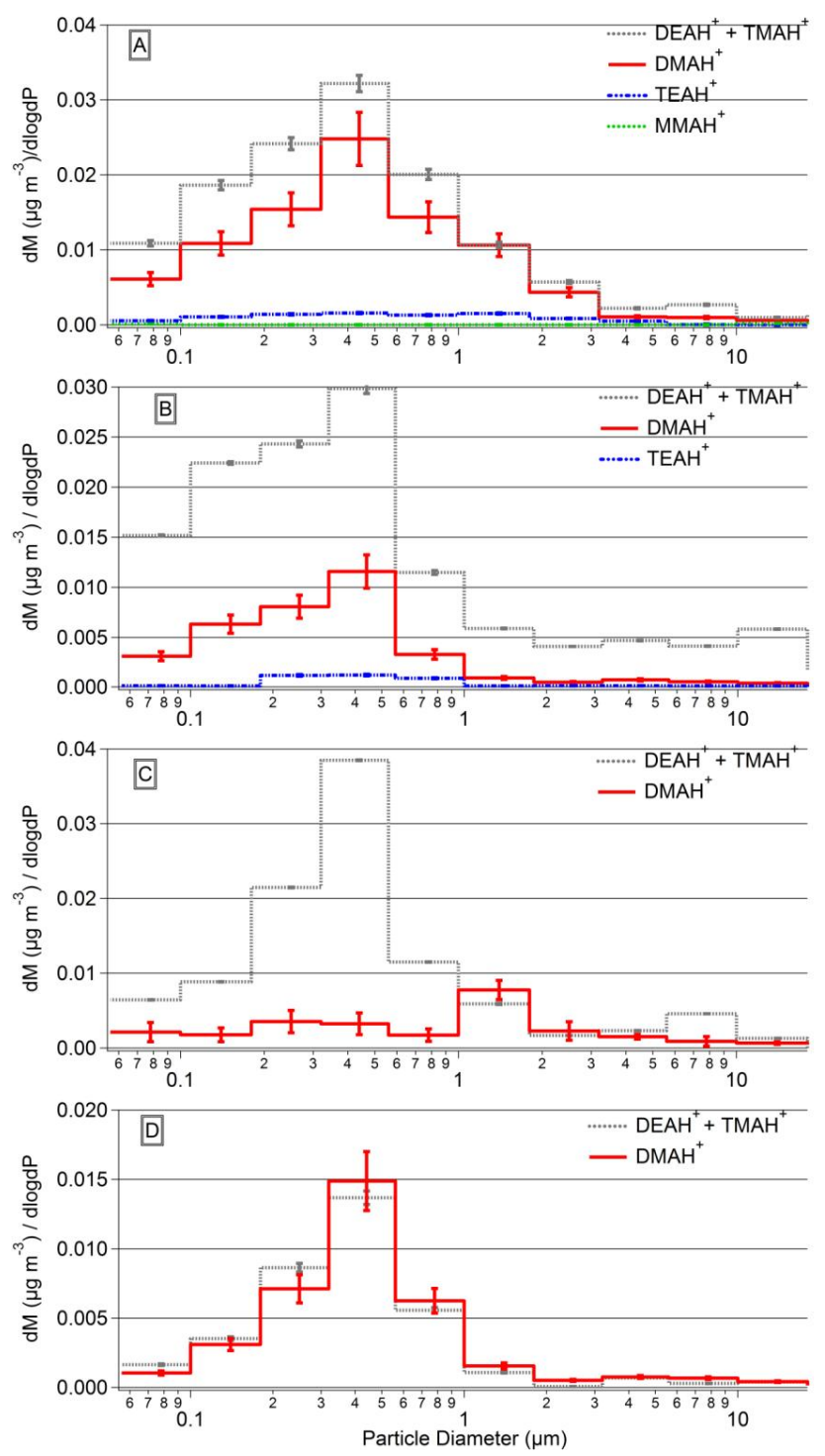

Fig. 4. Amine mass distributions as a function of particle diameter for (A) Sample 4 collected in Dorset, (B) Sample 3 collected in Toronto (C) Sample 8 collected in Lambton Shores, and (D) Sample 1 collected in Toronto.

amines better at limiting the $\mathrm{H}^{+}$freely available in solution, even when present in molar quantities more than an order of magnitude smaller than $\mathrm{NH}_{4}^{+}$.

\subsubsection{Size-dependence of alkyl amine mass}

Size distributions of amines by mass in samples collected at Dorset, Toronto and Lambton Shores, ON are shown in the panels of Fig. 4. The size dependence of the alkyl amines shows that their mass maximizes most often in the accumulation mode. The amines detected in our samples maximized in the $320-560 \mathrm{~nm}$ size range in 7 of 8 samples. Often, only tens of $\mathrm{ng} \mathrm{m}^{-3}$ were observed in the size bin with the largest contributions from $\mathrm{TMAH}^{+}+\mathrm{DEAH}^{+}$and $\mathrm{DMAH}^{+}$. The maximum mass loading of each amine detected in our samples and the size bin in which it maximized is given in Table 2. TEAH+, when present, showed the most variability in the distribution of the mass throughout the aerosol populations we collected. In Sample 6 (collected in Toronto) the abundance of TEAH+ was $14 \mathrm{ng} \mathrm{m}^{-3}$, the highest we encountered in this sample set, and was found to maximize in the $3.2-5.6 \mu \mathrm{m}$ size range.

The variety of amines detected changed based on sampling location and time of year. This could be due to changes in the source region of the air mass sampled, regional temperature and relative humidity, and seasonality as amine emissions are expected to increase with temperature and biological activity (Schade and Crutzen, 1995; Muller et al., 2009; Pratt et al., 2009). Figure 4a illustrates Sample 4 from Dorset, ON, which had the widest array of amines present in any sample collected. The sampled air mass originated over a region of south-western Ontario with a high density of agricultural activity, including animal husbandry, a likely source region for the primary emission of alkyl amines to the atmosphere. Two samples, one displayed in Fig. 4c, were collected in this source region at Lambton Shores to investigate particulate amines in proximity to presumed sources. During the collection period air originated over Michigan and the northern Great Lakes region of Ontario. Whether the amines we observed in Fig. 4c had partitioned from local emissions or were pre-existing components of transported aerosol is not possible to determine from these samples. The collected sample had $19 \mathrm{ng} \mathrm{m}^{-3}$ of $\mathrm{TMAH}^{+}+\mathrm{DEAH}^{+}$in the 320 $560 \mathrm{~nm}$ size bin, the highest detected mass of a single amine species in our samples. While the absolute mass loadings of amines seem comparable, or higher, in the downwind Dorset sample compared to the source region sample, it should be kept in mind that these samples were collected in the summer and spring, respectively. The seasonality of amine emissions and partitioning has been related to primary productivity (Muller et al., 2009; Sorooshian et al., 2009; Miyazaki et al., 2010) and local meteorology (Pratt et al., 2009). Online observations of both gas and $\mathrm{PM}_{2.5}$ ionic, water-soluble composition could yield more information in identifying source regions and thermodynamic factors that govern the partitioning of amines.

Figure $4 \mathrm{~b}$ from Toronto, ON shows an atypical amine mass loading compared to our other MOUDI samples collected in Toronto. The sampled air originated over central Ontario and Georgian Bay with similar amine loadings to those collected at the other two locations. Figure $4 \mathrm{~d}$ shows a more typical size-dependence of the mass loading of individual amines in our urban samples. In general, the observations from Figs. 3 and 4 show that even in instances where very large quantities of $\mathrm{NH}_{4}^{+}$were present throughout the fine mode, the presence of $\mathrm{DMAH}^{+}$and $\mathrm{TMAH}^{+}+$ $\mathrm{DEAH}^{+}$was observed. These observations are consistent with previous quantitative observations of alkyl amines in 
fine particulate samples (Sorooshian et al., 2008; Sorooshian et al., 2009). Our measurements show the size-resolved distributions throughout the sampled aerosol populations are also consistent with previous observations in marine atmospheres (Makela et al., 2001; Facchini et al., 2008; Muller et al., 2009; Violaki and Mihalopoulos, 2010; Miyazaki et al., 2010) with the maximum mass loadings seen in the accumulation mode, specifically from $320-560 \mathrm{~nm}$. Our observations are, to the best of our knowledge, the first to show the size-dependence of particulate alkyl amines in continental air masses.

\subsubsection{Size-dependence of $\mathrm{R}_{3} \mathrm{NH}^{+} / \mathrm{NH}_{4}^{+}$}

The dominance of $\mathrm{NH}_{4}^{+}$throughout the accumulation mode is most likely due to the ambient concentrations of $\mathrm{NH}_{3}$ being significantly higher than gas phase amines at our sampling sites (Sect. 3.2 provides evidence in Toronto). Typical $\mathrm{NH}_{3}$ measurements in south-western Ontario are on the order of a few ppb (Ellis et al., 2011). While alkyl amines are not routinely measured, they are expected to range from several ppb close to sources to ppt levels in the background atmosphere due to their short lifetime against $\mathrm{OH}$ ( $\tau \sim 1$ day). A higher ambient concentration of $\mathrm{NH}_{3}$ would allow its uptake to dominate the neutralization of the aerosol as growth by condensation occurs and the ratio of surface area to volume becomes more limited for reactive uptake. Theoretical calculations by Kurten et al. (2008) and Loukonen et al. (2010) have shown that small cluster formation of aminium salts with inorganic acids is thermodynamically favoured over ammonium salts. At smaller particle sizes (e.g. clusters $10 \mathrm{~nm}$ ), amines may be able to successfully out-compete $\mathrm{NH}_{3}$ due to thermodynamics of the system as shown experimentally (Murphy et al., 2007; Bzdek et al., 2010; Lloyd et al., 2009). As particles grow by condensation and reactive uptake, competition with $\mathrm{NH}_{3}$ for transport to the surface becomes dominant and the influence of relative concentrations supersedes the thermodynamic considerations.

To examine the size-dependence of the relative importance of amines versus ammonia, the molar ratio of the sum of amines to ammonium $\left(\mathrm{R}_{3} \mathrm{NH}^{+} / \mathrm{NH}_{4}^{+}\right)$detected in each sample was compared in Fig. 5. The error bars represent the uncertainty calculated based on the propagation of errors for the measured ammonium and only those amines that were detected in the sample. In most cases the observed ratio is wellconstrained because the amounts of all the considered analytes are above the instrument detection limits. Small quantities of all the analytes in the coarse mode produced larger uncertainties in those ratios. In all MOUDI samples, the molar ratio $\mathrm{R}_{3} \mathrm{NH}^{+} / \mathrm{NH}_{4}^{+}$showed one maximum below $200 \mathrm{~nm}$ and decreased as the particle size increased up to about $1 \mu \mathrm{m}$; the ratio then increased again in the coarse mode. All samples show this behaviour regardless of the absolute values of the $\mathrm{R}_{3} \mathrm{NH}^{+} / \mathrm{NH}_{4}^{+}$fraction. In the fine mode, maxima for an individual size bin ranged from ratios of 0.02 to 0.37 , with
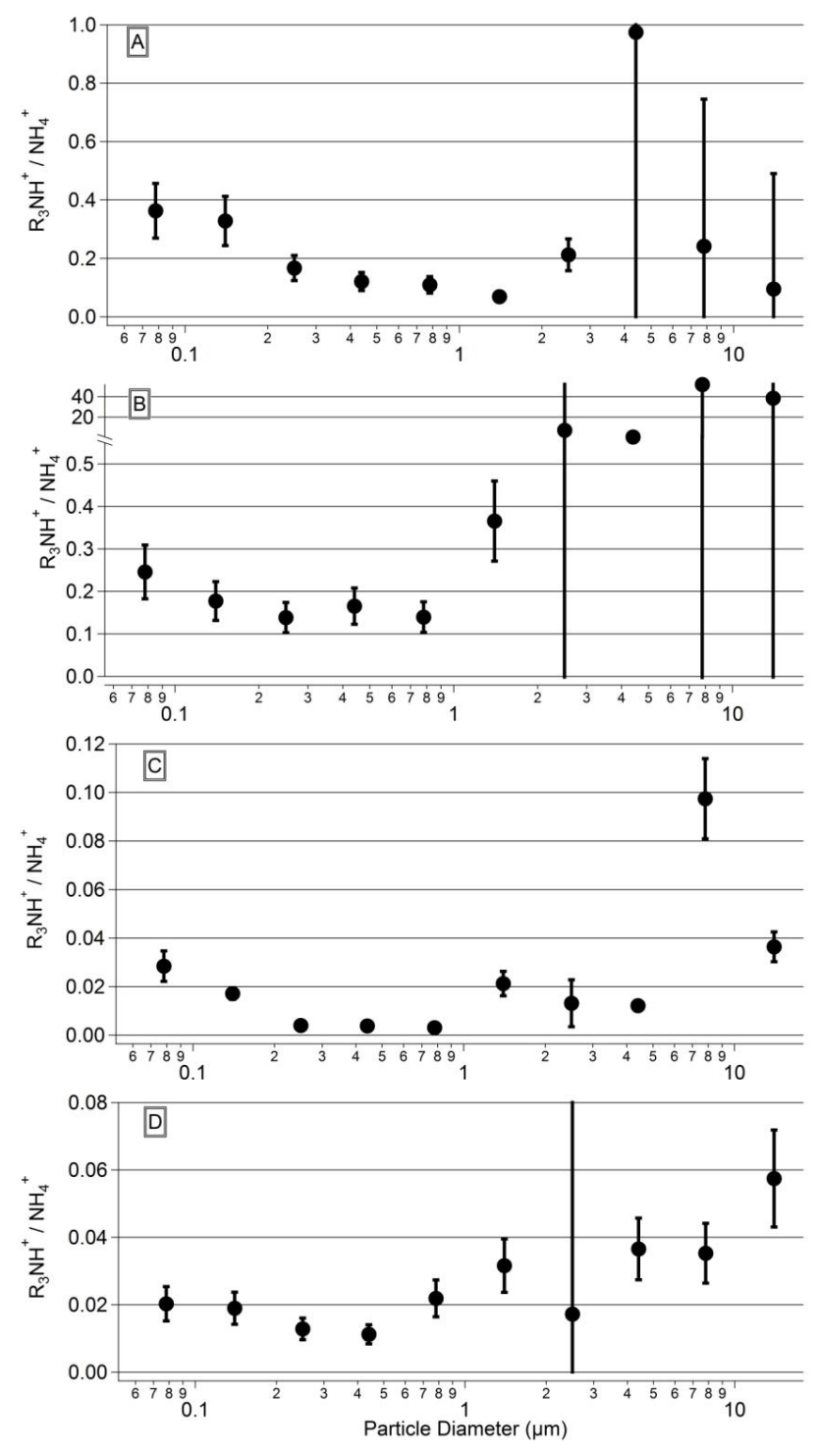

Fig. 5. Ratio of the sum of all particulate amines $\left(\mathrm{R}_{3} \mathrm{NH}^{+}\right)$measured to the total ammonium (moles/moles) as a function of particle diameter for (A) Sample 4 collected in Dorset, (B) Sample 3 collected in Toronto (C) Sample 8 collected in Lambton Shores, and (D) Sample 1 collected in Toronto.

the largest fraction being observed in a sample from Dorset, $\mathrm{ON}$ (Fig. 5a). A similar enhancement in $\mathrm{R}_{3} \mathrm{NH}^{+} / \mathrm{NH}_{4}^{+}$in excess of 0.30 was seen in Toronto (Fig. $5 b$ ) from an air mass also originating from south-western Ontario. However, most samples from the Toronto region typically show ratios below 0.04 (Fig. 5d). The samples collected at Lambton Shores (e.g. Fig. 5c), were in closer proximity to agriculturally active regions, but did not have ratios of $\mathrm{R}_{3} \mathrm{NH}^{+} / \mathrm{NH}_{4}^{+}$greater than 0.05 despite having the highest absolute amine mass loading of all the samples collected. The average molar ratio for $\mathrm{PM}_{1.8}$ in each sample is given in the final column on Table 1. 
These observations of amine composition in conjunction with other ionic aqueous species can help to inform models of particle formation and thermodynamic partitioning and predictions of aerosol properties, such as $\mathrm{pH}$ and hygroscopicity. The observations in Fig. 5 demonstrate that there is a strong size-dependence to the fine aerosol composition, especially with reference to the $\mathrm{R}_{3} \mathrm{NH}^{+} / \mathrm{NH}_{4}^{+}$ratio. In general, the amines contribute more importantly, in a relative sense, to the reduced nitrogen composition of particles with diameters $<200 \mathrm{~nm}$. Possible explanations include the higher thermodynamic stability of aminium salt clusters, or the preferential reactive uptake of amines by ultrafine particles with higher surface area-to-volume ratios. Alternately, particulate amines may be more susceptible to condensed phase reactions than ammonium, leading to their preferential degradation as particles age and grow. In the future, a back filter can be included to collect the smallest particles which may provide more information on nucleation mode particles. The maxima in the coarse mode are highly uncertain, but do appear to be significantly higher than the accumulation mode particles. From Fig. 3 and Fig. 4, it is evident that the coarse mode represents a population of particles with very different composition than the fine particles, and with lower absolute amounts of amines. The coarse mode amines may result from primary biogenic emissions, similar to enhanced marine coarse mode ON seen by Miyazaki et al. (2010) in highly biologically influenced aerosols, or reactive uptake on aqueous coarse mode aerosol that has been significantly aged by secondary acidification with $\mathrm{HNO}_{3}$. In either case, the ammonium signal in these coarse mode samples was near or below our instrument detection limits, enhancing the observed ratio when any amines are above their detection limits.

\subsection{Online detection of amines in the gas phase and $\mathbf{P M}_{2.5}$}

The utility of the information provided by the MOUDI data is limited by the long integration time necessary for collection and the absence of simultaneous gas phase measurements. To address these limitations, continuous online collection and analysis of gas and particle phase analytes was performed with the AIM-IC from 26 June-6 July 2009. This time period was characterized by cool and humid conditions, with rain events occurring from 09:00-14:00 and at 21:00 on 28 June, from 14:00-16:00 and 20:00-22:00 on 29 June, at 04:00 and 20:00 on 30 June, and at 22:00 on 1 July (all times are Eastern Daylight Savings). The north-westerly flow at the start and end of the campaign was interrupted by a period of south-westerly flow between 28 June and 1 July, and stagnant air early on 2 July. Amines were detected in both the gas and particle phases throughout the campaign. Figure 6 shows that amines in the gas phase (Panel A) were almost always at or near the instrument detection limits. Mixing ratios of DMA, and TMA + DEA ranged from below the detection limit to $2.7 \mathrm{ppt}$ for both sets of compounds. While observa-
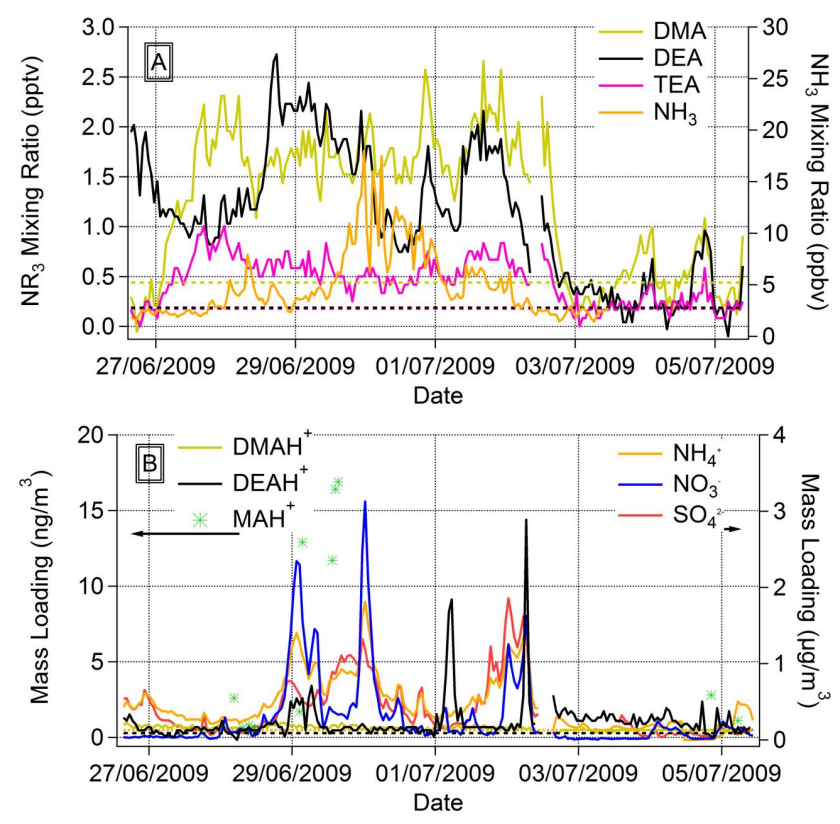

Fig. 6. Online AIM-IC observations of amines and dominant inorganic constituents in (A) the gas phase and (B) $\mathbf{P M}_{2.5}$. In each panel, the left axis applies to amines, and the right axis to inorganic consituents. Detection limits for amines are depicted using dashed lines.

tions of TEA are reported, the measured values were consistently below the detection limit. Amine emission sources in the Toronto area and their collective emission rates are not well-known, although particulate amines have been previously detected during new particle formation events (Tan et al., 2002). The variability in mixing ratio is not consistent across all species or with $\mathrm{NH}_{3}$, indicating different sources may exist for each. If local amine sources are limited, the observed abundances of a few ppt may be due to dilution and/or reaction with $\mathrm{OH}(\tau \sim 1$ day) prior to arriving at our sampling location.

Simultaneous observations of $\mathrm{NH}_{3}$ (Fig. 6a) showed mixing ratios ranging from 1-18 ppb. Therefore, the relative ratios of $\mathrm{NR}_{3} / \mathrm{NH}_{3}$ in the gas phase range from $1.6-$ $20 \times 10^{-3}$ over the course of our observations. According to the modelling studies by Murphy et al. (2007) and Barsanti et al. (2009), at this range of gaseous ratios, alkyl amines would seldom out-compete ammonia in bulk partitioning to the particle phase. Our particle observations showed only periodic amine mass loadings in $\mathrm{PM}_{2.5}$ above our online method detection limits. Figure 6 shows the sum of $\mathrm{TMAH}^{+}$ $+\mathrm{DEAH}^{+}$observed in the particle phase (Panel B) at mass loadings in the range of below detection limit to $16 \mathrm{ng} \mathrm{m}^{-3}$ The sporadic nature of the $\mathrm{MAH}^{+}$observations results from the difficulty in resolving this peak in the presence of much higher amounts of $\mathrm{NH}_{4}^{+}$. On two occasions, the increase in $\mathrm{TMAH}^{+}+\mathrm{DEAH}^{+}$coincided with mass loadings of $\mathrm{PM}_{2.5}$ $\mathrm{NO}_{3}^{-}$greater than $1 \mu \mathrm{g} \mathrm{m}^{-3}$, suggestive of the formation of 
aminium nitrate salts. However, early on $30 \mathrm{June}^{\mathrm{TMAH}}{ }^{+}$ $+\mathrm{DEAH}^{+}$was not detected when $\mathrm{NO}_{3}^{-}$was high and early on 1 July, it was observed despite $\mathrm{NO}_{3}^{-}$being lower than $0.1 \mu \mathrm{g} \mathrm{m}^{-3}$. Therefore, an increased presence of $\mathrm{NO}_{3}^{-}$in fine particulate matter does not appear to govern the presence and concentration of $\mathrm{TMAH}^{+}+\mathrm{DEAH}^{+}$. In Sorooshian et al. (2008), high amine mass loadings were measured by PILS-IC at the same time as positive values of excess nitrate, defined as the nitrate left over after sulfate and nitrate have been neutralized by the available ammonium, as measured by C-ToF-AMS. Values of excess nitrate inferred from the AIM-IC were zero within the uncertainty of the calculation, and this uncertainty is much larger than the mass loading of the observed amines. In our observations, it is more likely that the presence of nitrate in the particle phase is indicative of either high relative humidity or high nitric acid, both of which would be conducive to the partitioning of amines to the particle phase.

In most cases, increases in particulate amine loadings coincided with a decrease of amines in the gas phase, but mass balance was not observed (e.g. formation of $7.7 \mathrm{ng} \mathrm{m}^{-3}$ ( 2.54 pptv equivalent) of $\mathrm{TMAH}^{+}+\mathrm{DEAH}^{+}$on July 1 and a coincident decrease in $0.85 \mathrm{pptv}$ of TMA + DEA). This may be indicative of a sudden change in the total (gas + particle) amines during the time period or a slow time response to changing amine concentrations in our gas channel because of adsorption in our inlet. Such small amounts of amines partitioning to the particle phase make it challenging to use our online observations to determine if $\mathrm{R}_{3} \mathrm{NH}^{+}$is displacing $\mathrm{NH}_{4}^{+}$from particles because changes in the abundance of $\mathrm{NH}_{4}^{+}$smaller than $100 \mathrm{ng} \mathrm{m}^{-3}$ are below our measurement precision for that species.

While the online sampling campaign did not coincide with the collection dates of the Toronto MOUDI samples, some consistency may be expected between the $\mathrm{R}_{3} \mathrm{NH}^{+} / \mathrm{NH}_{4}^{+}$observed in both sets of samples. Based on the final column in Table 1, the molar ratio for $\mathrm{PM}_{1.8}$ in MOUDI samples ranged from $\sim 10^{-3}$ to $10^{-1}$. Because the online AIM-IC method has higher detection limits than the time-integrated MOUDI samples, at an $\mathrm{NH}_{4}^{+}$mass loading of $0.5 \mu \mathrm{g} \mathrm{m}^{-3}$, representative of the online sampling campaign, the lowest ratio we could quantitatively measure in hourly samples is $>10^{-2}$. In the MOUDI samples with similar $\mathrm{PM}_{1.8}$ mass loadings of $\mathrm{NH}_{4}^{+}$, the $\mathrm{R}_{3} \mathrm{NH}^{+} / \mathrm{NH}_{4}^{+}$ratio was always less than $1.5 \times 10^{-2}$. Based on the observed gas phase $\mathrm{NR}_{3} / \mathrm{NH}_{3}$ ratios of 1.6-20 $\times 10^{-3}$ (quantifiable because of high $\mathrm{NH}_{3}$ ), a $\mathrm{R}_{3} \mathrm{NH}^{+} / \mathrm{NH}_{4}^{+}$ratio in $\mathrm{PM}_{2.5}$ of $>10^{-2}$ would only be expected if amines are able to significantly outcompete ammonia based on thermodynamic considerations. Barsanti et al. (2009) and Murphy et al. (2007) suggested that the formation of stronger aminium salts with organic acids or nitric acid could favour preferential partitioning of amines to the particle phase. Particulate organic acids, such as oxalic acid, were not above the AIM-IC detection limits $\left(0.1 \mu \mathrm{g} \mathrm{m}^{-3}\right)$ during any of the online observation period. Because of the high humidity conditions during much of the campaign, the aerosol were likely aqueous, in which case partitioning according to Reaction (R1) may be most relevant. For example, the effective Henry's law constant for DEA (after accounting for protonation) is an order of magnitude higher than $\mathrm{NH}_{3}$, which would result in a stronger preference for partitioning to aqueous aerosol (Ge et al., 2011b). Observation periods spanning a wider range of atmospheric conditions would be valuable to assess the relative importance of meteorological conditions and chemical composition in dictating the gasparticle partitioning of atmospheric amines.

\section{Conclusions}

These measurements contribute to the small, but expanding, collection of ambient observations of atmospheric amines (Angelino et al., 2001; Makela et al., 2001; Tan et al., 2002; Denkenberger et al., 2007; Facchini et al., 2008; Sorooshian et al., 2008, 2009; Muller et al., 2009; Smith et al., 2010; Violaki and Mihalopoulos, 2010; Ge et al., 2011a). An advantage of the ion chromatography analysis described here is that the calibration protocol provides measurements (mass loadings or mixing ratios) with a high degree of precision for trace quantities ( $\mathrm{ng} \mathrm{m}^{-3}$ or $\mathrm{ppt}$ ). The sensitivity of the IC technique is a factor of 5-10 higher for the individual amines measured compared to ammonia, which contributes to the low instrument detection limits for the amines. Nevertheless, because in atmospheric samples ammonia/ammonium can be present in concentrations several orders of magnitude higher than the amines, it can impede the detection of some amines (e.g. methylamine and ethylamine) by this method. An ongoing issue with IC measurements of amines is the inability to resolve DEA and TMA. Because one, or both, of these amines appear to be among the most significant of the simple alkyl amines in atmospheric samples, and because their $\mathrm{K}_{H}$ and pKa values are quite different, it is highly desirable to achieve individual quantitative measurements.

Our MOUDI observations in one urban and two rural environments demonstrate consistent trends with respect to sizedependence: an absolute maximum of amine mass loading in $320-560 \mathrm{~nm}$ particles, and an increase in importance relative to ammonium for the smallest $(56-180 \mathrm{~nm})$ particles measured. The importance relative to ammonium in the coarse mode is less meaningful because ammonium was often below our detection limits, despite the presence of detectable levels of amines. In $\mathrm{PM}_{1.8}$ measurements, calculated by summing the six lowest MOUDI size bins, amines contributed tens of $\mathrm{ng} \mathrm{m}^{-3}$ and constituted between 0.3 and $10 \%$ of the water soluble particulate mass loading. To the best of our knowledge, the AIM-IC data represent the first simultaneous observations of gas and particle phase amine species with accompanying water-soluble ionic speciation in $\mathrm{PM}_{2.5}$ at hourly time resolution. Through online sampling 
in an urban environment, we observed instances of amines increasing in the particle phase at times with elevated $\mathrm{PM}_{2.5}$ nitrate. The mass loading of amines in $\mathrm{PM}_{2.5}$ never exceeded $20 \mathrm{ng} \mathrm{m}^{-3}$ during the online sampling period, a value too low to cause observable changes to the abundance of $\mathrm{NH}_{4}^{+}$or $\mathrm{NO}_{3}^{-}$. Observations made using this technique can provide data which is valuable in the evaluation of models designed to predict the contribution of amines to particle nucleation, or to bulk particle composition based on thermodynamic partitioning. However the size dependence of the $\mathrm{R}_{3} \mathrm{NH}^{+} / \mathrm{NH}_{4}^{+}$ ratio consistently seen in the MOUDI samples shows that an assumption that each size fraction of the fine aerosol population has the same relative composition as the bulk is not appropriate.

Acknowledgements. The AIM-IC was purchased with support from the Canada Foundation for Innovation and the Ontario Research Fund. The authors would like to thank: L. Oliver, V. Oldham and L. Yin for their contributions to method development, instrument operation and MOUDI sampling, and R. Ellis for ammonia measurements. Financial support for T. VandenBoer was provided through an Alexander Graham Bell Canada Graduate Scholarship from the Natural Sciences and Engineering Research Council of Canada (NSERC).

Edited by: F. Keutsch

\section{References}

Akyuz, M.: Simultaneous determination of aliphatic and aromatic amines in indoor and outdoor air samples by gas chromatography-mass spectrometry, Talanta, 71, 486-492, 2007.

Angelino, S., Suess, D. T., and Prather, K. A.: Formation of Aerosol Particles from Reactions of Secondary and Tertiary Alkylamines: Characterization by Aerosolo Time-of-Flight Mass Spectrometry, Environ. Sci. Technol., 35, 3130-3138, 2001.

Atkinson, R., Perry, R. A., and Pitts Jr., J. N.: Rate constants for the reaction of the $\mathrm{OH}$ radical with $\mathrm{CH}_{3} \mathrm{SH}$ and $\mathrm{CH}_{3} \mathrm{NH}_{2}$ over the temperature range 299-426K, J. Chem. Phys., 66, 1578-1581, 1977a.

Atkinson, R., Perry, R. A., and Pitts Jr., J. N.: Rate constants for the reactions of the $\mathrm{OH}$ radical with $\left(\mathrm{CH}_{3}\right)_{2} \mathrm{NH},\left(\mathrm{CH}_{3}\right)_{3} \mathrm{~N}$, and $\mathrm{C}_{2} \mathrm{H}_{5} \mathrm{NH}_{2}$ over the temperature range $298-426 \mathrm{~K}$, J. Chem. Phys., 68, 1850-1853, 1977b.

Atkinson, R., Baulch, D. L., Cox, R. A., Hampson, R. F., Kerr, J. A., Rossi, M. J., and Troe, J.: Evaluated kinetic, photochemical and heterogeneous data for atmospheric chemistry .5. IUPAC Subcommittee on Gas Kinetic Data Evaluation for Atmospheric Chemistry, J. Phys. Chem. Ref. Data, 26, 521-1011, 1997.

Barsanti, K. C., McMurry, P. H., and Smith, J. N.: The potential contribution of organic salts to new particle growth, Atmos. Chem. Phys., 9, 2949-2957, doi:10.5194/acp-9-2949-2009, 2009.

Bauer, S. E., Balkanski, Y., Schulz, M., Hauglustaine, D. A., and Dentener, F.: Global modeling of heterogeneous chemistry on mineral aerosol surfaces: Influence on tropospheric ozone chemistry and comparison to observations, J. Geophys. Res.-Atmos., 109, D02304, doi:10.1029/2003jd003868, 2004.
Berndt, T., Stratmann, F., Sipila, M., Vanhanen, J., Petaja, T., Mikkila, J., Gruner, A., Spindler, G., Mauldin, R. L., III, Curtius, J., Kulmala, M., and Heintzenberg, J.: Laboratory study on new particle formation from the reaction $\mathrm{OH}+\mathrm{SO}_{2}$ : influence of experimental conditions, $\mathrm{H}_{2} \mathrm{O}$ vapour, $\mathrm{NH}_{3}$ and the amine tert-butylamine on the overall process, Atmos. Chem. Phys., 10, 7101-7116, doi:10.5194/acp-10-7101-2010, 2010.

Bzdek, B. R., Ridge, D. P., and Johnston, M. V.: Amine exchange into ammonium bisulfate and ammonium nitrate nuclei, Atmos. Chem. Phys., 10, 3495-3503, doi:10.5194/acp-10-3495-2010, 2010.

Chang, I. H., Lee, C. G., and Lee, D. S.: Development of an automated method for simultaneous determination of low molecular weight aliphatic amines and ammonia in ambient air by diffusion scrubber coupled to ion chromatography, Anal. Chem., 75, 6141-6146, doi:10.1021/Ac0347314, 2003.

Denkenberger, K. A., Moffet, R. C., Holecek, J. C., Rebotier, T. P., and Prather, K. A.: Real-time,Single-particle Measurements of Oligomers in Aged Ambient Aerosol Particles, Environ. Sci. Technol., 41, 5439-5446, 2007.

Dinar, E., Anttila, R., and Rudich, Y.: CCN Activity and Hygroscopic Growth of Organic Aerosols Following Reactive Uptake of Ammonia, Environ. Sci. Technol., 42, 793-799, 2008.

Donaldson, D. J.: Adsorption of atmospheric gases at the air-water interface, I. NH 3 , J. Phys. Chem. A, 103, 62-70, 1999.

Ellis, R. A., Murphy, J. G., Pattey, E., van Haarlem, R., O’Brien, J. M., and Herndon, S. C.: Characterizing a Quantum Cascade Tunable Infrared Laser Differential Absorption Spectrometer (QCTILDAS) for measurements of atmospheric ammonia, Atmos. Meas. Tech., 3, 397-406, doi:10.5194/amt-3-397-2010, 2010.

Ellis, R. A., Murphy, J. G., Markovic, M., VandenBoer, T. C., Makar, P. A., Brook, J., and Mihele, C.: The influence of gasparticle partitioning and surface-atmosphere exchange on ammonia during BAQS-Met, Atmos. Chem. Phys., 11, 133-145, doi:10.5194/acp-11-133-2011, 2011.

Erupe, M. E., Liberman-Martin, A., Silva, P. J., Malloy, Q. G. J., Yonis, N., Cocker, D. R., and Purvis-Roberts, K. L.: Determination of methylamines and trimethylamine-N-oxide in particulate matter by non-suppressed ion chromatography, J. Chromatogr. A, 1217, 2070-2073, doi:10.1016/j.chroma.2010.01.066, 2010.

Facchini, M. C., Decesari, S., Rinaldi, M., Carbone, C., Finessi, E., Mircea, M., Fuzzi, S., Moretti, F., Tagliavini, E., Ceburnis, D., and O'Dowd, C. D.: Important Source of Marine Secondary Organic Aerosol from Biogenic Amines, Environ. Sci. Technol., 42, 9116-9121, 2008.

Finlayson-Pitts, B. J. and Pitts, J. N., Jr.: Chemistry of the upper and lower atmosphere: Theory, experiments, and applications, Academic Press, San Diego, CA, USA, 2000.

Ge, X., Wexler, A. S., and Clegg, S. L.: Atmospheric amines - Part I. A review, Atmos. Environ., 45, 524-546, doi:10.1016/j.atmosenv.2010.10.012, 2011a.

Ge, X., Wexler, A. S., and Clegg, S. L.: Atmospheric amines Part II. Thermodynamic properties and gas/particle partitioning, Atmos. Environ., 45, 561-577, 10.1016/j.atmosenv.2010.10.013, 2011b.

Gibb, S. W., Mantoura, R. F. C., and Liss, P. S.: Ocean-atmosphere exchange and atmospheric speciation of ammonia and methylamines in the region of the NW Arabian Sea, Global Biogeochem. Cy., 13, 161-177, 1999. 
Goodman, A. L., Underwood, G. M., and Grassian, V. H.: A laboratory study of the heterogeneous reaction of nitric acid on calcium carbonate particles, J. Geophys. Res.-Atmos., 105, 2905329064, 2000.

Gronberg, L., Lovkvist, P., and Jonsson, J. A.: Measurement of Aliphatic-Amines in Ambient Air and Rainwater, Chemosphere, 24, 1533-1540, 1992.

Hanisch, F., and Crowley, J. N.: The heterogeneous reactivity of gaseous nitric acid on authentic mineral dust samples, and on individual mineral and clay mineral components, Phys Chem Chem Phys, 3, 2474-2482, 2001.

Huang, G., Hou, J., and Zhou, X. L.: A Measurement Method for Atmospheric Ammonia and Primary Amines Based on Aqueous Sampling, OPA Derivatization and HPLC Analysis, Environ. Sci. Technol., 43, 5851-5856, doi:10.1021/Es900988q, 2009.

Junninen, H., Ehn, M., Petaja, T., Luosujarvi, L., Kotiaho, T., Kostiainen, R., Rohner, U., Gonin, M., Fuhrer, K., Kulmala, M., and Worsnop, D. R.: A high-resolution mass spectrometer to measure atmospheric ion composition, Atmos. Meas. Tech., 10, 10391053, doi:10.5194/amt-10-1039-2010, 2010.

Kouvarakis, G., Doukelis, Y., Mihalopoulos, N., Rapsomanikis, S., Sciare, J., and Blumthaler, M.: Chemical, physical and optical characterization of aerosols during PAUR II experiment, J. Geophys. Res., 107, 8141, 10.1029/2000JD000291, 2002.

Kurten, T., Loukonen, V., Vehkamaki, H., and Kulmala, M.: Amines are likely to enhance neutral and ion-induced sulfuric acid-water nucleation in the atmosphere more effectively than ammonia, Atmos. Chem. Phys., 8, 4095-4103, doi:10.5194/acp8-4095-2008, 2008.

Liu, Y., Gibson, E. R., Cain, J. P., Wang, H., Grassian, V. H., and Laskin, A.: Kinetics of heterogeneous reaction of $\mathrm{CaCO}_{3}$ particles with gaseous $\mathrm{HNO}_{3}$ over a wide range of humidity, J. Phys. Chem. A, 112, 1561-1571, doi:10.1021/Jp076169h, 2008.

Lloyd, J. A., Heaton, K. J., and Johnston, M. V.: Reactive Uptake of Trimethylamine into Ammonium Nitrate Particles, J. Phys. Chem. A, 113, 4840-4843, doi:10.1021/Jp900634d, 2009.

Loukonen, V., Kurten, T., Ortega, I. K., Vehkamaki, H., Padua, A. A. H., Sellegri, K., and Kulmala, M.: Enhancing effect of dimethylamine in sulfuric acid nucleation in the presence of water - a computational study, Atmos. Chem. Phys., 10, 49614974, doi:10.5194/acp-10-4961-2010, 2010.

MacDougall, D. and Crummett, W. B.: Guidelines for data acquisition and data quality evaluation in environmental chemistry, Anal. Chem., 52, 2242-2249, 10.1021/ac50064a004, 1980.

Mackay, D., Shiu, W. Y., Ma, K. C., and Lee, S. C.: Aliphatic Amines, 2 ed., Handbook of Physical-Chemical Properties and Environmental Fate for Organic Chemicals, Taylor \& Francis Group, 13 pp., 2004.

Makela, J. M., Yli-Koivisto, S., Hiltunen, V., Seidl, W., Swietlicki, E., Teinila, K., Sillanpaa, M., Koponen, I. K., Paatero, J., Rosman, K., and Hameri, K.: Chemical composition of aerosol during particle formation events in boreal forest, Tellus B, 53, 380 393, 2001.

Marple, V., Rubow, K., Ananth, G., and Fissan, H. J.: Micro-Orifice Uniform Deposit Impactor, J. Aerosol Sci., 17, 489-494, 1986.

Miyazaki, Y., Kawamura, K., and Sawano, M.: Size distributions of organic nitrogen and carbon in remote marine aerosols: Evidence of marine biological origin based on their isotopic ratios, Geophys. Res. Lett., 37, L06803, doi:10.1029/2010g1042483, 2010.
Mmereki, B. T., Hicks, J. M., and Donaldson, D. J.: Adsorption of atmospheric gases at the air-water interface. 3: Methylamines, J. Phys. Chem. A, 104, 10789-10793, doi:10.1021/Jp0023258, 2000.

Mopper, K. and Zika, R. G.: Free Amino-Acids in Marine Rains Evidence for Oxidation and Potential Role in Nitrogen Cycling, Nature, 325, 246-249, 1987.

Mosier, A. R., Andre, C. E., and Viets, F. G.: Identification of Aliphatic-Amines Volatilized from Cattle Feedyard, Environ. Sci. Technol., 7, 642-644, 1973.

Mozurkewich, M.: The Dissociation-Constant of AmmoniumNitrate and Its Dependence on Temperature, Relative-Humidity and Particle-Size, Atmos. Environ. a-Gen, 27, 261-270, 1993.

Muller, C., Iinuma, Y., Karstensen, J., van Pinxteren, D., Lehmann, S., Gnauk, T., and Herrmann, H.: Seasonal variation of aliphatic amines in marine sub-micrometer particles at the Cape Verde islands, Atmos. Chem. Phys., 9, 9587-9597, doi:10.5194/acp-99587-2009, 2009.

Murphy, S. M., Sorooshian, A., Kroll, J. H., Ng, N. L., Chhabra, P., Tong, C., Surratt, J. D., Knipping, E., Flagan, R. C., and Seinfeld, J. H.: Secondary aerosol formation from atmospheric reactions of aliphatic amines, Atmos. Chem. Phys., 7, 2313-2337, doi:10.5194/acp-7-2313-2007, 2007.

Pankow, J. F.: Gas/particle partitioning of neutral and ionizing compounds to single and multi-phase aerosol particles. 1. Unified modeling framework, Atmos. Environ., 37, 3323-3333, doi:10.1016/S1352-2310(03)00346-7, 2003.

Pastor, S. H., Allen, J. O., Hughes, L. S., Bhave, P., Cass, G. R., and Prather, K. A.: Ambient single particle analysis in Riverside, California by aerosol time-of-flight mass spectrometry during the SCOS97-NARSTO, Atmos. Environ., 37, S239-S258, doi:10.1016/S1352-2310(03)00393-5, 2003.

Pitts, J. N., Jr., Grosjean, D., Van Cauwenberghe, K., Schmid, J. P., and Fitz, D. R.: Photooxidation of aliphatic amines under simulated atmospheric conditions: formation of nitrosamines, nitramines, amides, and photochemical oxidant, Environ. Sci. Technol., 12, 946-953, 1978.

Pratt, K. A., Hatch, L. E., and Prather, K. A.: Seasonal Volatility Dependence of Ambient Particle Phase Amines, Environ. Sci. Technol., 43, 5276-5281, doi:10.1021/Es803189n, 2009.

Rabaud, N. E., Ebeler, S. E., Ashbaugh, L. L., and Flocchini, R. G.: Characterization and quantification of odorous and nonodorous volatile organic compounds near a commercial dairy in California, Atmos. Environ., 37, 933-940, doi:10.1016/S13522310(02)00970-6, 2003.

Schade, G. W. and Crutzen, P. J.: Emission of Aliphatic-Amines from Animal Husbandry and Their Reactions - Potential Source of $\mathrm{N}_{2} \mathrm{O}$ and HCN, J. Atmos. Chem., 22, 319-346, 1995.

Seinfeld, J. H. and Pandis, S. N.: Ammonia-Water Equilibrium, in: Atmospheric Chemistry and Physics: From Air Pollution to Climate Change, 2 ed., John Wiley \& Sons, Inc., Hoboken, NJ, USA, 299 pp., 2006.

Silva, P. J., Erupe, M. E., Price, D., Elias, J., Malloy, Q. G. J., Li, Q., Warren, B., and Cocker, D. R.: Trimethylamine as precursor to secondary organic aerosol formation via nitrate radical reaction in the atmosphere, Environ. Sci. Technol., 42, 4689-4696, doi:10.1021/Es703016v, 2008.

Smith, J. N., Dunn, M. J., VanReken, T. M., Iida, K., Stolzenburg, M. R., McMurry, P. H., and Huey, L. G.: Chemical com- 
position of atmospheric nanoparticles formed from nucleation in Tecamac, Mexico: Evidence for an important role for organic species in nanoparticle growth, Geophys. Res. Lett., 35(5), L04808, doi:10.1029/2007GL032523, 2008.

Smith, J. N., Barsanti, K. C., Friedli, H. R., Ehn, M., Kulmala, M., Collins, D. R., Scheckman, J. H., Williams, B. J., and McMurry, P. H.: Observations of aminium salts in atmospheric nanoparticles and possible climatic implications, P. Natl. Acad. Sci. USA, 107, 6634-6639, 2010.

Sorooshian, A., Murphy, S. N., Hersey, S., Gates, H., Padro, L. T., Nenes, A., Brechtel, F. J., Jonsson, H., Flagan, R. C., and Seinfeld, J. H.: Comprehensive airborne characterization of aerosol from a major bovine source, Atmos. Chem. Phys., 8, 5489-5520, doi:10.5194/acp-8-5489-2008, 2008.

Sorooshian, A., Padró, L. T., Nenes, A., Feingold, G., McComiskey, A., Hersey, S. P., Gates, H., Jonsson, H. H., Miller, S. D., Stephens, G. L., Flagan, R. C., and Seinfeld, J. H.: On the link between ocean biota emissions, aerosol, and maritime clouds: Airborne, ground, and satellite measurements off the coast of California, Global Biogeochem. Cy., 23, GB4007, doi:10.1029/2009gb003464, 2009.

Spurny, K. R.: Analytical Chemistry of Aerosols, 18 ed., Lewis, Boca Raton, FL, USA, 1999.
Tan, P. V., Evans, G. J., Tsai, J., Owega, S., Fila, M. S., and Malpica, O.: On-line analysis of urban particulate matter focusing on elevated wintertime aerosol concentrations, Environ. Sci. Technol., 36, 3512-3518, 2002.

Van Neste, A., Duce, R. A., and Lee, C.: Methylamines in the marine atmosphere, Geophys. Res. Lett., 14, 711-714, 1987.

Veltman, K., Singh, B., and Hertwich, E. G.: Human and Environmental Impact Assessment of Postcombustion $\mathrm{CO} 2$ Capture Focusing on Emissions from Amine-Based Scrubbing Solvents to Air, Environ. Sci. Technol., 44, 1496-1502, doi:10.1021/Es902116r, 2010.

Violaki, K. and Mihalopoulos, N.: Water-soluble organic nitrogen (WSON) in size-segregated atmospheric particles over the Eastern Mediterranean, Atmos. Environ., 4339-4345, 2010.

Vlasenko, A., Sjogren, S., Weingartner, E., Stemmler, K., Gaggeler, H. W., and Ammann, M.: Effect of humidity on nitric acid uptake to mineral dust aerosol particles, Atmos. Chem. Phys., 6, 21472160, doi:10.5194/acp-6-2147-2006, 2006.

Ye, Y., Tsai, C. J., Pui, D. Y. H., and Lewis, C. W.: Particle Transmission Characteristics of an Annular Denuder Ambient Sampling System, Aerosol Sci. Tech., 14, 102-111, 1991. 